\title{
Changes in depression in a cohort of Danish HIV-positive individuals: time for routine screening
}

\author{
Lotte Rodkjaer $^{\mathrm{A}, \mathrm{E}}$, Tinne Laursen ${ }^{\mathrm{A}}$, Nils B. Christensen ${ }^{\mathrm{B}}$, Kirsten Lomborg ${ }^{\mathrm{C}}$, \\ Lars Ostergaard ${ }^{\mathrm{A}}$ and Morten Sodemann ${ }^{\mathrm{D}}$ \\ ADepartment of Infectious Diseases, Aarhus University Hospital, Skejby, DK-8200 Aarhus N., Denmark. \\ ${ }^{B}$ The Research Clinic for Functional Disorders and Psychosomatic, Aarhus University Hospital, \\ DK-8200 Aarhus N., Denmark. \\ ${ }^{\mathrm{C}}$ Department of Nursing Science, School of Public Health, Aarhus University, DK-8000 Aarhus C., \\ Denmark. \\ Department of Infectious Diseases, Odense University Hospital, DK-5000 Odense, Denmark. \\ ${ }^{\mathrm{E}}$ Corresponding author. Email: Lottrodk@rm.dk
}

\begin{abstract}
Background: The aim of this study was to follow a cohort of HIV-positive individuals for 3 years in order to assess changes in depression, adherence, unsafe sex and emotional strains from living with HIV. Methods: Participants were assessed for depression, adherence, emotional strain and unsafe sex via a questionnaire. The Beck Depression Inventory II (BDI) was used to assess the prevalence and severity of depressive symptoms. Patients with a BDI score of 20 or above (moderate to major depression) were offered a clinical evaluation by a consultant psychiatrist. Results: In 2005, 205 HIV-positive individuals participated in the study. Symptoms of depression (BDI >14) were observed in 77 (38\%) and major depression (BDI $\geq 20)$ in $53(26 \%)$ individuals. In 2008, 148 participants were retested (72\% of original sample). Depression (BDI >14) was observed in $38(26 \%)$ and symptoms of major depression (BDI $\geq 20)$ in $24(16 \%)$ individuals. Patients at risk of moderate to major depression were more likely to be non-adherent to medications, to practice unsafe sex and to suffer from emotional strains compared with patients not at risk of depression, both at baseline (2005) and follow-up (2008). Conclusion: This study demonstrated a decline in depression scores over time and an association between the risk of depression and low medication adherence, stress and unsafe sex. We recommend routine screening for depression to be conducted regularly to provide full evaluations and relevant psychiatric treatment.
\end{abstract}

Additional keywords: adherence, AIDS, compliance, psychiatry, psychological factors, stress.

\section{Introduction}

Depression is the most common form of psychological distress experienced by individuals with HIV or AIDS. ${ }^{1,2}$ Up to onethird of people living with HIV or AIDS have been shown to have mood disorders or clinically significant depressive symptoms. ${ }^{3}$ Individuals living with HIV have a two-fold greater risk of major depression than HIV-negative controls. ${ }^{4}$ Treatment of depression is critical for several reasons. The diagnosis of HIV infection is typically a traumatic event, ${ }^{5}$ and depression compounds the physical and emotional stress associated with HIV. Studies examining the impact of stressful events on changes in disease markers have suggested that psychological factors may affect HIV disease progression. Depression, depressive symptoms and psychological stress have also been associated with poor adherence to highly active antiretroviral treatment (HAART). ${ }^{6,7}$ Furthermore, several studies that examined depression at the initiation of HAART found that, compared with non-depressed patients, patients with depression exhibited over five times the risk of clinical progression to AIDS, ${ }^{2,8}$ slower viral suppression ${ }^{9}$ and shorter survival. ${ }^{10}$ Thus, depression has been associated with deterioration in psychosocial functioning, reduced immune response, more rapid progression of HIV and higher mortality rates. ${ }^{11-14}$ Studies have found that depression was also associated with unsafe sex (unsafe sex is defined as unprotected intercourse (including anal intercourse) with a partner of opposite or unknown HIV status) and thus, increased the risk of transmitting or contracting HIV. ${ }^{15,16}$

HIV infection tends to advance very slowly. The most compelling evidence for the role of depression in this disease comes from studies of cohorts over long intervals. ${ }^{2}$ Several recent studies have reported conflicting rates of depression due to differences in diversity in the populations sampled, variations in assessment methods and differences in study timeframes. These factors have complicated the ability to compare findings across studies; ${ }^{1,17}$ thus, it is impractical to arrive at a mean estimate of the prevalence of depression associated with HIV.

Due to these challenges, depression has been underrecognised and undertreated. ${ }^{1,17,18}$ Many studies have relied solely on self-reported symptom scales to assess depression. 
However, the 'gold standard' is to combine self-reported symptom scales with structured psychiatric interviews by a professional mental health investigator. ${ }^{1,19}$

In 2005, we used the 'gold standard' to investigate the risk of depression in people at a single HIV clinic in Denmark and the factors associated with that risk. We found signs of depression in over one-third of the HIV-positive patients. Moreover, before the beginning of the study, over one-quarter of the people had untreated moderate or major depression. ${ }^{16}$

The aims of this study were to follow up that cohort of HIVpositive individuals for 3 years in order to assess changes in their risk of depression, HAART adherence, the emotional strains of living with HIV, and unsafe sex.

\section{Methods}

\section{Study participants}

From May 2005 to September 2005, 391 HIV-positive patients were recruited from the Department of Infectious Diseases at Aarhus University Hospital, Skejby. For inclusion, patients had to be diagnosed with HIV, aged 18 or older, and able to read and write in Danish. Fifty patients were excluded who could not read or write Danish; thus, 341 patients were enrolled in the study. All patients gave written informed consent before participation. Of those eligible for the study, $73.9 \%(n=252)$ responded to the questionnaire and 205 participants completed the Beck Depression Inventory II (BDI) questionnaire correctly. ${ }^{16,20}$ Therefore, a total of $205 \mathrm{HIV}$-positive patients were included in the study.

During the same months in $2008,72 \%$ of patients were retested with the questionnaires $(n=148)$. A packet was mailed to each person that included a questionnaire, patient information and a prepaid response envelope. Reasons for not responding included death $(n=4)$, consultation at another hospital $(n=10)$ and no specific reason $(n=43)$. The withdrawal of the 57 non-responders in 2008 did not change the comparability of the characteristics between the 2005 and 2008 cohorts.

The outpatient clinic at the Department of Infectious Diseases at Aarhus University Hospital provides care for $11 \%$ of the total HIV-positive population in Denmark. The patients in this study were representative of the total Danish HIV-positive population ( $n=3968$ total) regarding gender, age, route of infection and HIV exposure, but were not representative regarding injected drug use, because only a few injected drug users participated in this study. ${ }^{21}$ The study population was also comparable to the total Danish HIV-positive population regarding baseline characteristics of the disease. ${ }^{21}$ The study was approved by the Aarhus Health's Human Research Ethics Committee and the Danish Data Protection Agency. Development of the questionnaire used in both 2005 and 2008 was described previously. ${ }^{19}$ The questionnaires regarding unsafe sex were asked; 'During the last year, how often did you have unprotected intercourse or anal intercourse with a partner of opposite or unknown HIV status?' The question could be answered with the following options: 'never', 'less than half of the time', 'more than half of the time' or 'always'.

The questions regarding adherence were (1) 'How often did you forget to take your HIV medicine during the last 4 days?' and (2) 'Did you stop taking HIV medicine for 7 days or more during the last 12 months?' The first question could be answered with 'none', '1 day', '2 days', '3 days' or '4 days'; the second could be answered with 'yes' or 'no'.

The question regarding the emotional strain of living with HIV was asked "Are there some of the following feelings that have an emotional strain in relation to HIV in your daily life? Guilt, shame, anxiety, concerns, stress, loneliness, HIV influences my whole life, constant thoughts about HIV, live a double life with HIV as a secret, HIV limits my way of living and stigmatisation.' The patient had the following options to answer each emotional strain: 'not at all', 'a little', 'somewhat' or 'a lot'.

\section{Depression measurements}

The $\mathrm{BDI}^{20}$ was used to assess the prevalence and severity of depressive symptoms. The BDI has shown high validity and reliability in measuring depressive symptoms, and it has shown acceptable test-retest reliability $(r=0.79)$ in a nonclinical population. Respondents were required to rate 21 items from 0 to 3 according to how they had felt during the preceding 2 weeks. The BDI focuses on both the cognitive-affective symptoms of depression, e.g. pessimism and diminished self-esteem; and the somatic symptoms of depression, e.g. weight loss. A BDI score $\geq 14$ is widely accepted as an indication of depression. In this study, the score categories included: 0-13 - minimal depression; 14-19 - mild depression; 20-28- moderate depression; 29-63-major depression. Scores $\leq 20$ were validated with the Hamilton Depression Scale. ${ }^{22}$

The Hamilton Depression Scale (HDS-17) was used to validate the diagnoses of minimal to moderate depression based on the scores of the BDI. The HDS-17 consists of a semi-structured interview with 17 items. Scores represent a synthesis of severity and frequency of occurrence. The score categories included: 7-12-mild depression; 13-20-moderate depression; $>20-$ severe depression. $^{22}$

\section{Diagnosis of depression based on medical records}

Data on diagnosed depression were also obtained from the medical records of those that did not respond to the questionnaires (non-responders) in both 2005 and 2008.

\section{Procedures}

All patients with a BDI score of 20 or above were offered a clinical interview by a consultant psychiatrist. The consultant psychiatrist also checked all questionnaires with cut-offs between 14 and 19, and interviewed 10 randomly selected patients to be sure that the patients were not at risk of depression or committing suicide. The result of the BDI was documented in the medical records to ensure follow-up of patients who declined an interview with the consultant psychiatrist.

\section{Statistical analysis}

We conducted statistical analyses with STATA 10 (StataCorp LP, College Station, TX, USA). All data were double-entered. The primary endpoint at baseline was the prevalence of 
symptoms of depression (according to the BDI). We used unadjusted and adjusted (multiple) logistic regression models to determine the relationship between the dependent variable (depression) and independent variables (e.g. psychological factors). Statistical significance was defined as $P<0.05$. Variables significant in each of the multivariate models were tested in a final multivariate model by backwards elimination with $P<0.05$.

\section{Results}

In 2005 (baseline), 205 HIV-positive patients participated. Symptoms of depression (BDI >14) were observed in 77 $(38 \%)$ and symptoms of moderate to major depression (BDI $\geq 20)$ in $53(26 \%)$ patients. Among the 148 patients that were reexamined in 2008 (follow-up), symptoms of depression (BDI $>14)$ were observed in $38(26 \%)$ and symptoms of moderate to major depression (BDI $\geq 20)$ in $24(16 \%)$. In both 2005 and 2008 , more patients had a history of depression after they were

Table 1. Prevalence of the severity of depression (based on the Beck Depression Inventory II score (BDI)) and history of depression at baseline (2005) and follow-up (2008)

\begin{tabular}{lrrrr}
\hline & \multicolumn{2}{c}{2005} & \multicolumn{2}{c}{2008} \\
& $n=205$ & $\%$ of $n$ & $n=148$ & $\%$ of $n$ \\
\hline BDI score & & & & \\
$\quad$ Minimal (0-13) & 128 & 62 & 110 & 74 \\
Mild (14-19) & 24 & 12 & 14 & 10 \\
$\quad$ Moderate (20-28) & 30 & 15 & 9 & 6 \\
$\quad$ Major (29-63) & 23 & 11 & 15 & 10 \\
History of depression & & & & \\
$\quad$ Pre-HIV diagnosis & 16 & 25 & 9 & 6 \\
$\quad$ Post-HIV diagnosis & 48 & 75 & 46 & 31 \\
\hline
\end{tabular}

diagnosed with HIV (Table 1). The HDS-17 categories of depression correlated well with those determined by the BDI. Of the 53 patients found at risk of moderate to major depression during follow-up, 16 had had a BDI $\geq 20$ both at baseline and follow-up due to periodic depression. The mean BDI scores at both baseline and follow-up were in the range of major depression. Twenty-one patients had a BDI $\geq 20$ at baseline, but not at follow-up; these had recovered from depression. Eight patients were at risk of moderate to major depression at follow-up, but not at baseline (Fig. 1).

Univariate analyses conducted in 2005 and 2008 indicated a higher risk of moderate to major depression among patients who had primary and secondary school $<9$ years, no higher education, received unemployment benefits, were undergoing rehabilitation, received sickness or disability benefits, and experienced their financial situation as hopeless (Table 2). We conducted an unadjusted odds ratio analysis to determine whether depression was associated with the emotional strain of living with HIV. We found that the degree of emotional strain was significantly associated with the risk of depression, both in 2005 and 2008 (Table 3). In multivariate analyses, only stress was independently associated with the risk of depression, both in 2005 and 2008 (Table 4).

Patients at risk of moderate to major depression were more likely to have missed at least one dose of HAART in the 4 days before assessment in 2005, and they were more likely to have stopped HAART for 7 days or more during the last 12 months in 2008 (Table 5).

At baseline, the risk of moderate to major depression was correlated with unsafe sex, the number of partners ( $>10$ partners the last year) and a dissatisfying sex life. We found a trend in the degree of depression with respect to the frequency of unsafe sex. At follow-up, we observed a $1 \%$ increase compared with baseline (Table 6). However, due to the fact that there were

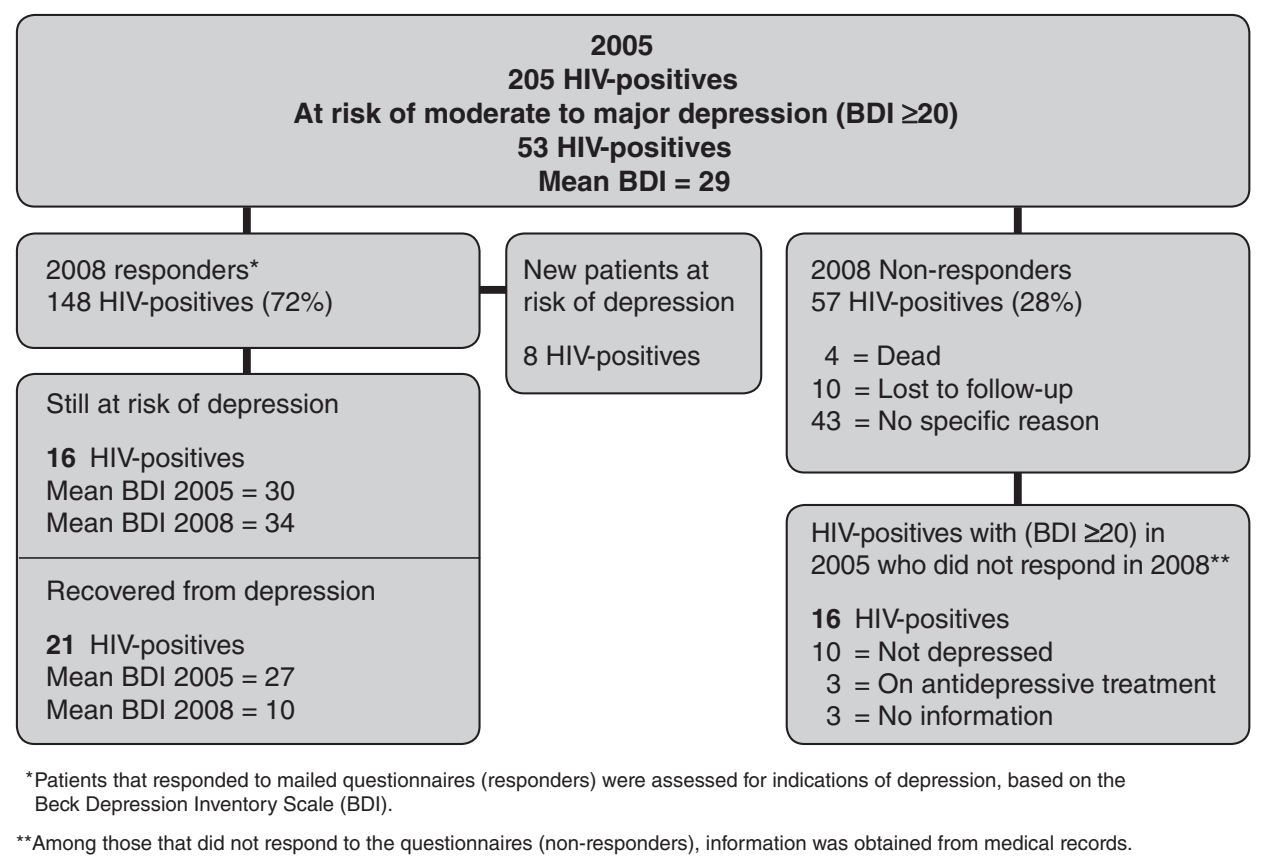

Fig. 1. Risk of depression in a cohort of HIV-positive patients at baseline (2005) and follow-up (2008). 
Table 2. Data on demographic and risk of depression at baseline (2005) and follow-up (2008)

\begin{tabular}{|c|c|c|c|c|}
\hline & & Baseline & & llow-up \\
\hline & $n=205$ & Depressed $n(\%)^{\mathrm{A}}$ & $n=148$ & Depressed $n(\%)$ \\
\hline Gender & & & & \\
\hline Female & $49(24)$ & $14(29)$ & $32(22)$ & $5(16)$ \\
\hline Male & $156(76)$ & $39(25)$ & $116(78)$ & $19(16)$ \\
\hline Age (years) & & & & \\
\hline $18-29$ & $12(6)$ & $2(17)$ & $21(14)$ & $3(14)$ \\
\hline $30-44$ & $81(40)$ & $24(30)$ & $65(44)$ & $11(17)$ \\
\hline $45-59$ & $89(43)$ & $24(27)$ & $55(37)$ & $9(16)$ \\
\hline $60+$ & $23(11)$ & $3(13)$ & $7(5)$ & $1(14)$ \\
\hline Ethnicity & & & & \\
\hline White & $165(80)$ & $38(23)$ & $128(86)$ & $18(14)$ \\
\hline Other ethnicities & $40(20)$ & $15(38)$ & $20(14)$ & $6(30)$ \\
\hline Married or living with partner & & & & \\
\hline Yes & $87(42)$ & $21(24)$ & $51(35)$ & $9(18)$ \\
\hline Have a partner, but live alone & & & & \\
\hline Yes & $19(9)$ & $5(26)$ & $35(24)$ & $6(17)$ \\
\hline Have a partner & & & & \\
\hline Yes & $55(27)$ & $15(27)$ & $35(24)$ & $9(26)$ \\
\hline Education & & & & \\
\hline Primary or secondary school $<9$ years & $49(24)$ & $13(27)$ & $39(26)$ & $7(18)$ \\
\hline Primary or secondary school $>9$ years & $149(73)$ & $38(25)$ & $109(74)$ & $17(16)$ \\
\hline Unknown & $7(3)$ & $2(28)$ & & \\
\hline Further education & & & & \\
\hline Short course length of higher education & $34(17)$ & $8(24)$ & $28(19)$ & $3(11)$ \\
\hline Medium course length of higher education & $104(51)$ & $23(22)$ & $77(52)$ & $13(17)$ \\
\hline Long course of higher education & $18(8)$ & $6(33)$ & $18(12)$ & $2(11)$ \\
\hline No higher education & $23(11)$ & $9(39)$ & $15(10)$ & $3(20)$ \\
\hline Other & $9(4)$ & $1(11)$ & $7(7)$ & $3(43)$ \\
\hline Unknown & $17(8)$ & $5(29)$ & & \\
\hline Employment & & & & \\
\hline Employed & $88(43)$ & $15(17)$ & $74(50)$ & $8(11)$ \\
\hline Unemployment benefit, rehabilitation, social security & $24(12)$ & $11(45)$ & $6(4)$ & $4(67)$ \\
\hline Sickness or disability support pension & $43(21)$ & $14(33)$ & $39(26)$ & $7(18)$ \\
\hline Student & $8(3)$ & $1(13)$ & $2(1)$ & 0 \\
\hline Pensioner or part time & $22(11)$ & $5(23)$ & $16(11)$ & $4(25)$ \\
\hline Subsidised flexible job & $12(6)$ & $3(25)$ & 0 & 0 \\
\hline Other & $8(4)$ & $4(50)$ & $11(7)$ & $1(9)$ \\
\hline Experience finances as hopeless & & & & \\
\hline Yes & $17(8)$ & $12(71)$ & $7(5)$ & $4(60)$ \\
\hline No & $188(92)$ & $41(22)$ & $141(95)$ & $20(14)$ \\
\hline Route of infection & & & & \\
\hline Sexual & $172(83)$ & $46(27)$ & $122(83)$ & $22(18)$ \\
\hline Blood transfusion & $13(6)$ & $3(23)$ & $6(4)$ & 0 \\
\hline Injected drug use & $5(2)$ & $2(40)$ & $2(1)$ & 0 \\
\hline Unknown & $15(7)$ & $2(13)$ & $18(12)$ & $2(11)$ \\
\hline HIV exposure groups & & & & \\
\hline Homosexual & $114(56)$ & $34(30)$ & $67(45)$ & $10(15)$ \\
\hline Heterosexual & $87(42)$ & $18(20)$ & $67(45)$ & $11(16)$ \\
\hline Bisexual & $4(2)$ & $1(25)$ & $8(5)$ & $2(25)$ \\
\hline Unknown & 0 & 0 & $6(4)$ & $1(13)$ \\
\hline
\end{tabular}

${ }^{\mathrm{A}}$ The percentage of depressed patients in that category.

fewer patients at risk for depression at follow-up than at baseline, it was not possible to test for a trend.

\section{Discussion}

The findings in this study indicated that individuals infected with HIV experienced high levels of depressive symptoms, but screening and treatment for depression was associated with a decline in the prevalence of depression.
We found patients with undiagnosed depression, both at baseline in $2005(n=18)^{16}$ and at follow-up in $2008(n=8)$, and these subsequently started treatment (medication, psychological consultation or both). We also found that the level of moderate and major risk of depression declined significantly between baseline and follow-up, presumably due to the increase in the number of patients that started treatment after the results of the first survey. 
Table 3. Data on the emotional strains of living with HIV at follow-up (2008) Baseline data is presented in: Rodkjaer et al. ${ }^{16} \mathrm{NA}$, not applicable

\begin{tabular}{|c|c|c|c|c|}
\hline \multirow[t]{2}{*}{ HIV-associated feelings } & \multicolumn{4}{|c|}{ Follow-up } \\
\hline & $n=148$ & Depressed $n(\%)$ & $\begin{array}{l}\text { Unadjusted odds ratio } \\
\text { (95\% confidence interval) }\end{array}$ & $P$-value \\
\hline \multicolumn{5}{|l|}{ Guilt } \\
\hline Not at all & $102(69)$ & $11(11)$ & 1 (Reference) & \multirow[t]{4}{*}{0.06} \\
\hline A little & $25(17)$ & $7(28)$ & $3.2(1.1-9.5)$ & \\
\hline Somewhat & $14(9)$ & $4(29)$ & $3.3(0.8-12.4)$ & \\
\hline A lot & $6(4)$ & $2(33)$ & $4.1(0.6-25.5)$ & \\
\hline \multicolumn{5}{|l|}{ Shame } \\
\hline Not at all & $84(57)$ & $9(11)$ & 1 (Reference) & \multirow[t]{4}{*}{0.02} \\
\hline A little & $37(25)$ & $5(14)$ & $1.3(0.4-4.2)$ & \\
\hline Somewhat & $18(12)$ & $7(39)$ & $5.3(1.6-17.3)$ & \\
\hline A lot & $8(5)$ & $3(38)$ & $5.0(1.0-24.8)$ & \\
\hline \multicolumn{5}{|l|}{ Anxiety } \\
\hline Not at all & $70(47)$ & $4(6)$ & 1 (Reference) & \multirow[t]{4}{*}{0.00} \\
\hline A little & $53(36)$ & $7(13)$ & $2.5(0.7-9.2)$ & \\
\hline Somewhat & $16(11)$ & $6(38)$ & $10.05(2.4-41.9)$ & \\
\hline A lot & $8(5)$ & $7(88)$ & $117.2(11.4-1199.6)$ & \\
\hline \multicolumn{5}{|l|}{ Concerns } \\
\hline Not at all & $40(27)$ & 0 & 1 (Reference) & \multirow[t]{4}{*}{0.00} \\
\hline A little & $71(48)$ & $8(11)$ & $5.2(0.6-43.1)$ & \\
\hline Somewhat & $23(16)$ & $8(35)$ & $21.8(2.5-189.8)$ & \\
\hline A lot & $12(8)$ & $7(58)$ & $57.4(5.8-567.8)$ & \\
\hline \multicolumn{5}{|l|}{ Stress } \\
\hline Not at all & $76(51)$ & $3(4)$ & 1 (Reference) & \multirow[t]{4}{*}{0.00} \\
\hline A little & $42(28)$ & $5(12)$ & $3.33(0.7-14.7)$ & \\
\hline Somewhat & $17(11)$ & $6(35)$ & $13.4(18.3-830.5)$ & \\
\hline A lot & $12(8)$ & $10(83)$ & $123.3(18.3-830.5)$ & \\
\hline \multicolumn{5}{|l|}{ Loneliness } \\
\hline Not at all & $80(54)$ & $2(3)$ & 1 (Reference) & \multirow[t]{4}{*}{0.00} \\
\hline A little & $38(26)$ & $7(18)$ & $5.8(1.4-24.1)$ & \\
\hline Somewhat & $19(13)$ & $7(37)$ & $15.1(3.4-66.8)$ & \\
\hline A lot & $10(7)$ & $7(70)$ & $60.6(10.2-358.7)$ & \\
\hline \multicolumn{5}{|c|}{ HIV influences my whole life } \\
\hline Not at all & $87(59)$ & $4(5)$ & 1 (Reference) & \multirow[t]{4}{*}{0.00} \\
\hline A little & $40(27)$ & $6(15)$ & $2.9(0.8-10.3)$ & \\
\hline Somewhat & $14(9)$ & $8(58)$ & $22.4(5.5-90.0)$ & \\
\hline A lot & $5(3)$ & $5(100)$ & NA & \\
\hline \multicolumn{5}{|c|}{ Constant thoughts about HIV } \\
\hline Not at all & $94(64)$ & $7(7)$ & 1 (Reference) & \multirow[t]{4}{*}{0.00} \\
\hline A little & $39(26)$ & $6(15)$ & $2.2(0.7-7.3)$ & \\
\hline Somewhat & $9(6)$ & $6(67)$ & $25.1(5.1-122.7)$ & \\
\hline A lot & $5(3)$ & $5(100)$ & NA & \\
\hline Live a double life with $\mathrm{H}$ & & & & \\
\hline Not at all & $78(53)$ & $6(8)$ & 1 (Reference) & 0.02 \\
\hline A little & $30(20)$ & $6(20)$ & $2.5(0.7-8.4)$ & \\
\hline Somewhat & $24(16)$ & $5(21)$ & $2.7(0.7-9.4)$ & \\
\hline A lot & $15(10)$ & $6(40)$ & $6.8(1.8-24.9)$ & \\
\hline HIV limits my way of li & & & & \\
\hline Not at all & $61(41)$ & 0 & 1 (Reference) & 0.00 \\
\hline A little & $40(27)$ & $4(10)$ & $6.7(0.7-63.0)$ & \\
\hline Somewhat & $29(20)$ & $11(38)$ & $37.2(4.5-308.5)$ & \\
\hline A lot & $17(11)$ & $8(47)$ & $54.2(6.0-486.1)$ & \\
\hline Stigmatisation & & & & \\
\hline Not at all & $67(45)$ & $3(4)$ & 1 (Reference) & 0.00 \\
\hline A little & $45(30)$ & $7(16)$ & $3.0(0.8-11.2)$ & \\
\hline Somewhat & 19 (13) & $6(32)$ & $7.7(1.9-31.2)$ & \\
\hline A lot & $13(9)$ & $7(54)$ & $19.5(4.4-86.3)$ & \\
\hline
\end{tabular}


Table 4. The emotional strains of living with HIV at baseline (2005) and follow-up (2008) Adjusted odds ratio shows the odds of depression associated with the degree of stress. Adjusted for guilt, shame, anxiety, concerns, stress, loneliness, influence of HIV on respondent's life, constant thoughts about HIV, living a double life with HIV as a secret, HIV limiting way of life and stigmatisation

\begin{tabular}{lcccc}
\hline & $\begin{array}{c}\text { Adjusted odds ratio } \\
\text { (95\% confidence interval (CI)) } \\
\text { Baseline }\end{array}$ & $\begin{array}{c}P \text {-value } \\
\text { Adjusted odds ratio } \\
(95 \% \text { CI) }\end{array}$ & $P$-value \\
\hline Stress & & & 1 (reference) & \\
Not at all & 1 (reference) & 0.68 & $6.2(0.7-55.2)$ & 0.10 \\
A little & $0.7(0.23-2.6)$ & 0.09 & $14.2(1.6-134.2)$ & 0.02 \\
Somewhat & $3.0(0.83-11.5)$ & 0.00 & $70(6.5-742.2)$ & 0.00 \\
A lot & $13.5(2.8-63.3)$ & & \\
\hline
\end{tabular}

Table 5. Adherence to antiretroviral treatment and relative risk of depression among HIV-positive patients at baseline (2005) and follow-up (2008)

HAART, highly active antiretroviral therapy; CI, confidence interval

\begin{tabular}{|c|c|c|c|c|}
\hline & \multicolumn{2}{|c|}{2005} & \multicolumn{2}{|c|}{2008} \\
\hline & $\begin{array}{c}n \\
205(\%)\end{array}$ & $\begin{array}{c}\text { Depressed } \\
n(\%)\end{array}$ & $\begin{array}{c}n \\
148(\%)\end{array}$ & $\begin{array}{c}\text { Depressed } \\
n(\%)\end{array}$ \\
\hline \multicolumn{5}{|c|}{ On HAART } \\
\hline Yes & $164(80)$ & $42(26)$ & $131(88)$ & $22(17)$ \\
\hline \multirow[t]{2}{*}{ No } & $41(20)$ & $11(27)$ & $17(12)$ & $2(12)$ \\
\hline & Relative risk & $P$-value & Relative risk & $P$-value \\
\hline \multicolumn{5}{|c|}{ Forgot to take HAART during the last 4 days } \\
\hline No & 1 (reference group) & & 1 & \\
\hline Yes & $2.8 \mathrm{CI}(1.7-4.6)$ & 0.00 & $1.8 \mathrm{CI}(1.0-3.6)$ & 0.07 \\
\hline \multicolumn{5}{|c|}{ Stopped taking HAART for 7 days or more during the last 12 months } \\
\hline No & 1 & & 1 & \\
\hline Yes & $2.1 \mathrm{CI}(0.6-7.5)$ & 0.24 & $6.1 \mathrm{CI}(2.0-18.7)$ & 0.00 \\
\hline
\end{tabular}

Table 6. Degree of depression (based on Beck Depression Inventory II (BDI) score) and self-reported unsafe sex in HIV-positive patients at baseline (2005) and follow-up (2008)

Test for trend $P=0.03$ in 2005

\begin{tabular}{|c|c|c|c|c|c|c|c|c|}
\hline \multirow[b]{2}{*}{ Level of depression } & \multicolumn{4}{|c|}{ Baseline } & \multicolumn{4}{|c|}{ Follow-up } \\
\hline & Minimal & Mild & Moderate & Major & Minimal & Mild & Moderate & Major \\
\hline BDI & $0-13$ & $14-19$ & $20-28$ & $29-63$ & $0-13$ & $14-19$ & $20-28$ & $29-63$ \\
\hline \multicolumn{9}{|l|}{$\%$ of HIV-positive patients } \\
\hline Unsafe sex ${ }^{\mathrm{A}}$ & 30 & 38 & 57 & 57 & 22 & 14 & 33 & 33 \\
\hline$>10$ partners the last year & 11 & 4 & 10 & 17 & 10 & 7 & 11 & 0 \\
\hline Not satisfied with sex life & 42 & 75 & 80 & 87 & 45 & 71 & 89 & 87 \\
\hline
\end{tabular}

${ }^{\mathrm{A}}$ Unsafe sex $=$ unprotected intercourse (including anal intercourse) with a partner of opposite or unknown HIV status.

Our results corroborated those of Gibbie et al., who found that $34.8 \%$ of patients with HIV (AIDS) had scored $>14$ on the BDI scale and $27 \%$ of those met the criteria for current depression after consulting a psychiatrist; furthermore, after a 2-year follow-up, they also found a decline in the depression scores. ${ }^{19}$ In fact, the rates of depression have varied considerably among studies, due to differences in measures, timeframes, settings and risk groups. In this study, we used the 'gold standard' measure, which included two validated methods (BDI and HDS-17), supplemented with a structured clinical interview by a consultant psychiatrist. Therefore, the present study was likely to provide a representative estimate of the true prevalence of moderate to major depression among patients with HIV. ${ }^{17,19}$ In the Danish HIV population, $10 \%$ were infected through injected drug use. ${ }^{21}$ Thus, our study population was not representative of the entire HIV-positive population in Denmark. $^{21}$ This might have biased our estimates towards a lower prevalence of depression, because the prevalence of depression in the group of substance abusers is reportedly high. $^{23,24}$ Atkinson et al. found that symptomatic HIV disease (AIDS), but not solely HIV infection, increased the intermediate-term risk of major depression, and that a previous psychiatric history could predict future vulnerability. ${ }^{24}$ In our cohort, one out of four patients had a history of depression before the HIV diagnosis, but three out of four had a history of depression after the HIV diagnosis. This underlines the importance of preventing depression in these patients. 
The present study had some limitations. Depressive symptoms tend to change over time; therefore, a crosssectional study will miss $\sim 20-25 \%$ of depressed patients. This is because BDI scores are less likely to identify previously depressed patients that are presently taking medication and patients with periodic symptoms of depression. $^{17}$ We do not have information on patient compliance to the antidepressive treatment recommended by the psychiatrist. It is well known that many patients discontinue treatment before completing an acceptable 3-month regimen and that patients with depression can recover without antidepressive treatment. ${ }^{25}$ The study itself might have increased the attention and focus on symptoms of depression, both among the patients and the providers, which also could have led to a reduction in depressive symptoms.

Both at baseline and follow-up, there was a higher risk of moderate to major depression (BDI $\geq 20$ ) among patients who received unemployment benefits, were undergoing rehabilitation, received sickness or disability benefits, or experienced their financial situation as hopeless.

As the demographic factors among patients at risk of depression were comparable at baseline and follow-up, including the abovementioned variables, the decline in depression could not be explained by a change in these.

Depression plays a role in the decision to stop working and acts as a barrier for returning to work once health is stable. In a longitudinal study, the major predictors of unemployment, in order of influence, were financial considerations (patients receiving disability benefits were less likely to work), psychiatric factors (past or current diagnosis of major depression), medical status, cognitive factors and education. Unemployment has previously been associated with higher rates of depressive symptoms, lower quality of life, and higher levels of HIV RNA with lower CD4 counts. ${ }^{26}$ With improvements in HIV treatments, individuals have been able to continue work, which has been associated with a better quality of life, less psychological distress and increased socioeconomic status. $^{26,27}$

We found that HIV-related emotions, as presented in Table 3 including guilt, shame, anxiety, concerns, stress, loneliness, HIV influences my whole life, constant thoughts about HIV, live a double life with HIV as a secret, HIV limits my way of living and stigmatisation, were associated with a higher risk of depressive symptoms, in accordance with the existing literature. ${ }^{15}$ These factors were not part of the BDI inventory, and they may represent independent HIV-specific factors for identifying vulnerable HIV patients that require special attention. HIV presents individuals with multiple challenges that may overwhelm their coping resources and impair psychological adjustment to the ongoing demands of managing this stigmatised chronic illness. $8,28,29$ Both depression $^{5,29}$ and a stressful life ${ }^{5,29}$ have been linked to more rapid HIV disease progression and lower survival rates. ${ }^{30}$ Stress is difficult to define, because it can describe many conditions. For example, it can refer to the strain involved in coping with the illness, to the physical and mental changes taking place in the body, and to an individual's sense of inadequacy. Qualitative studies are needed to provide further information for refining our definition of stress in this context.
Our group is currently conducting a qualitative study to investigate stressors related to HIV. Moreover, although there are a variety of quality indicators for the care of depression designed for investigations of general populations, there is not a set of quality indicators for the care of depression in the context of HIV. ${ }^{31}$

In this study, patients at risk of moderate to major depression (BDI $\geq 20$ ) had a higher risk of non-adherence to HAART. Several studies have shown an association between depression and non-adherence to medication related to HIV. 6,32 Furthermore, antidepressant treatment has been shown to improve adherence to HAART. ${ }^{33}$ Understanding the contribution of depression and depression treatments on adherence to HAART might enable clinicians to make earlier identifications and to prescribe more aggressive treatments among this population.

We also found that depression was associated with unsafe sex, consistent with findings in the existing literature. ${ }^{15,16}$ Furthermore, depression, non-adherence and unsafe sex were associated with the risk of transmitting HIV or contracting HIV. $^{15,16}$

We suggest that screening for depression should be conducted regularly, for example every year, when patients have symptoms that overlap with those of an HIV infection (i.e. poor appetite, weight loss, loss of energy, insomnia). In particular, patients should be screened for depression at the time of HIV diagnosis, before initiating HAART, to provide a full evaluation and relevant psychiatric treatment. Future research should examine psychological variables related to HIVpositivity that may provide specific indicators of elevated depressive symptomatology.

In conclusion, we found that symptoms of depression declined in our cohort from 2005 to 2008. Depression was associated with non-adherence, unsafe sex and psychological factors. These results suggested that treating depressed HIVpositive patients could improve adherence to HAART, reduce the risk of transmission of HIV and improve quality of life. We recommend that screening of HIV-positive patients for depression should be conducted regularly to provide a full evaluation and relevant psychiatric treatment.

\section{Conflicts of interest}

None declared.

\section{Acknowledgements}

This project was funded by Aarhus University Hospital, Skejby Research Foundation, The Health Insurance Foundation, The Central Denmark Region Health Research Foundation and The Lundbeck Foundation. The authors are grateful to all participants, without whom this work would not have been possible.

\section{References}

1 Rabkin JG. HIV and depression: review and update. Curr HIV/AIDS Rep 2008; 5: 163-71. doi:10.1007/s11904-008-0025-1

2 Leserman J. Role of depression, stress, and trauma in HIV disease progression. Psychosom Med 2008; 70: 539-45. doi:10.1097/PSY. 0b013e3181777a5f 
3 Bing EG, Burnam MA, Longshore D, Fleishman JA, Sherbourne CD, London AS, et al. Psychiatric disorders and drug use among human immunodeficiency virus-infected adults in the United States. Arch Gen Psychiatry 2001; 58: 721-8. doi:10.1001/archpsyc.58.8.721

4 Ciesla JA, Roberts JE. Meta-analysis of the relationship between HIV infection and risk for depressive disorders. Am J Psychiatry 2001; 158 : 725-30. doi:10.1176/appi.ajp.158.5.725

5 Leserman J, Petitto JM, Gu H, Gaynes BN, Barroso J, Golden RN, et al. Progression to AIDS, a clinical AIDS condition and mortality: psychosocial and physiological predictors. Psychol Med 2002; 32: 1059-73. doi:10.1017/S0033291702005949

6 DiMatteo MR, Lepper HS, Croghan TW. Depression is a risk factor for noncompliance with medical treatment: meta-analysis of the effects of anxiety and depression on patient adherence. Arch Intern Med 2000; 160: 2101-7. doi:10.1001/archinte.160.14.2101

7 Chander G, Himelhoch S, Moore RD. Substance abuse and psychiatric disorders in HIV-positive patients: epidemiology and impact on antiretroviral therapy. Drugs 2006; 66: 769-89. doi:10.2165/00003 495-200666060-00004

8 Bouhnik AD, Préau M, Vincent E, Carrieri MP, Gallais H, Lepeu G, et al. Depression and clinical progression in HIV-infected drug users treated with highly active antiretroviral therapy. Antivir Ther 2005; 10: 53-61.

9 Pence BW, Miller WC, Gaynes BN, Eron JJ Jr. Psychiatric illness and virologic response in patients initiating highly active antiretroviral therapy. J Acquir Immune Defic Syndr 2007; 44: 159-66. doi:10.1097/ QAI.0b013e31802c2f51

10 Lima VD, Geller J, Bangsberg DR, Patterson TL, Daniel M, Kerr T, et al. The effect of adherence on the association between depressive symptoms and mortality among HIV-infected individuals first initiating HAART. AIDS 2007; 21: 1175-83. doi:10.1097/QAD.0b0 13e32811ebf57

11 Ickovics JR, Hamburger ME, Vlahov D, Schoenbaum EE, Schuman P, Boland RJ, et al. Mortality, CD4 cell count decline, and depressive symptoms among HIV-seropositive women: longitudinal analysis from the HIV Epidemiology Research Study. JAMA 2001; 285: 1466-74. doi:10.1001/jama.285.11.1466

12 Leserman J. HIV disease progression: depression, stress, and possible mechanisms. Biol Psychiatry 2003; 54: 295-306. doi:10.1016/S00063223(03)00323-8

13 Cruess DG, Evans DL, Repetto MJ, Gettes D, Douglas SD, Petitto JM. Prevalence, diagnosis, and pharmacological treatment of mood disorders in HIV disease. Biol Psychiatry 2003; 54: 307-16. doi:10.1016/S0006-3223(03)00318-4

14 Alciati A, Gallo L, Monforte AD, Brambilla F, Mellado C. Major depression-related immunological changes and combination antiretroviral therapy in HIV-seropositive patients. Hum Psychopharmacol 2007; 22: 33-40. doi:10.1002/hup.813

15 Berg CJ, Michelson SE, Safren SA. Behavioral aspects of HIV care: adherence, depression, substance use, and HIV-transmission behaviours. Infect Dis Clin North Am 2007; 21: 181-200. doi:10.1016/j.idc.2007.01.005

16 Rodkjaer L, Laursen T, Balle N, Sodemann M. Depression in patients with HIV is under-diagnosed: a cross-sectional study in Denmark. HIV Med 2010; 11: 46-53. doi:10.1111/j.1468-1293.2009.00741.x

17 Treisman GJ, Angelino AF. The psychiatry of AIDS. A guide to diagnosis and treatment. Baltimore, MD: The John Hopkins University Press; 2004.

18 Asch SM, Kilbourne AM, Gifford AL, Burnam MA, Turner B, Shapiro MF, et al. Under-diagnosis of depression in HIV: who are we missing? J Gen Intern Med 2003; 18: 450-60. doi:10.1046/j.15251497.2003.20938.x
19 Gibbie T, Mijch A, Ellen S, Hoy J, Hutchison C, Wright E, et al. Depression and neurocognitive performance in individuals with HIV/ AIDS: 2-year follow-up. HIV Med 2006; 7: 112-21. doi:10.1111/ j.1468-1293.2006.00350.x

20 Beck AT, Ward CH, Mendelson M, Mock J, Erbaugh J. An inventory for measuring depression. Arch Gen Psychiatry 1961; 4: 561-71.

21 Lohse N, Hansen AB, Jensen-Fangel S, Kronborg G, Kvinesdal B, Pedersen C, et al. Demographics of HIV-1 infection in Denmark: results from the Danish HIV Cohort Study. Scand J Infect Dis 2005; 37: 338-43. doi:10.1080/00365540510031692

22 Hamilton M. Development of a rating scale; for primary depressive illness. Br J Soc Clin Psychol 1967; 6: 278-96.

23 Dew MA, Becker JT, Sanchez J, Caldararo R, Lopez OL, Wess J, et al. Prevalence and predictors of depressive, anxiety and substance use disorders in HIV-infected and uninfected men: a longitudinal evaluation. Psychol Med 1997; 27: 395-409.

24 Atkinson JH, Grant I. Natural history of neuropsychiatric manifestations of HIV disease. Psychiatr Clin North Am 1994; 17: $17-33$.

25 Olfson M, Marcus SC, Tedeschi M, Wan GJ. Continuity of antidepressant treatment for adults with depression in the United States. Am J Psychiatry 2006; 163: 101-8. doi:10.1176/appi.ajp.163. 1.101

26 Blalock AC, McDaniel JS, Farber EW. Effect of employment on quality of life and psychological functioning in patients with HIV/ AIDS. Psychosomatics 2002; 43: 400-4. doi:10.1176/appi.psy.43. 5.400

27 Dray-Spira R, Gueguen A, Lert F, VESPA Study Group. Disease severity, self-reported experience of workplace discrimination and employment loss during the course of chronic HIV disease: differences according to gender and education. Occup Environ Med 2008; 65: 112-9. doi:10.1136/oem.2007.034363

28 Scott-Sheldon LA, Kalichman SC, Carey MP, Fielder RL. Stress management interventions for HIV+ adults: a meta-analysis of randomized controlled trials, 1989 to 2006. Health Psychol 2008; 27: 129-39. doi:10.1037/0278-6133.27.2.129

29 Ironson G, O'Cleirigh C, Fletcher MA, Laurenceau JP, Balbin E, Klimas N, et al. Psychosocial factors predict CD4 and viral load change in men and women with human immunodeficiency virus in the era of highly active antiretroviral treatment. Psychosom Med 2005; 67: 1013-21. doi:10.1097/01.psy.0000188569.58998.c8

30 Carrico AW, Antonia MH. Effects of psychological interventions on neuroendocrine hormone regulation and immune status in HIVpositive persons: a review of randomized controlled trials. Psychosom Med 2008; 70: 575-84. doi:10.1097/PSY.0b013e3181 $7 \mathrm{a} 5 \mathrm{~d} 30$

31 Pyne JM, Asch SM, Lincourt K, Kilbourne AM, Bowman C, Atkinson $\mathrm{H}$, et al. Quality indicators for depression care in HIV patients. AIDS Care 2008; 20: 1075-83. doi:10.1080/09540120701796884

32 Starace F, Ammassari A, Trotta MP, Murri R, De Longis P, Izzo C, et al. NeuroICoNA Study Group. Depression is a risk factor for suboptimal adherence to highly active antiretroviral therapy. $J$ Acquir Immune Defic Syndr 2002; 31: S136-9.

33 Yun LW, Maravi M, Kobayashi JS, Barton PL, Davidson AJ. Antidepressant treatment improves adherence to antiretroviral therapy among depressed HIV-infected patients. J Acquir Immune Defic Syndr 2005; 38: 432-8. doi:10.1097/01.qai.0000147524. 19122.fd

Manuscript received 9 June 2010, accepted 7 September 2010 